\title{
Regional Visibility Statistics in the United States: Natural and Transboundary Pollution Influences, and Implications for the Regional Haze Rule
}

\section{Citation}

Park, Rokjin J., Daniel J. Jacob, Naresh Kumar, and Robert M. Yantosca. 2006. Regional visibility statistics in the United States: Natural and transboundary pollution influences, and implications for the regional haze rule. Atmospheric Environment 40(28): 5405-5423.

\section{Published Version}

doi:10.1016/j.atmosenv.2006.04.059

\section{Permanent link}

http://nrs.harvard.edu/urn-3:HUL.InstRepos:3743672

\section{Terms of Use}

This article was downloaded from Harvard University's DASH repository, and is made available under the terms and conditions applicable to Other Posted Material, as set forth at http:// nrs.harvard.edu/urn-3:HUL.InstRepos:dash.current.terms-of-use\#LAA

\section{Share Your Story}

The Harvard community has made this article openly available.

Please share how this access benefits you. Submit a story.

\section{Accessibility}




\title{
Regional visibility statistics in the United States: Natural and transboundary pollution influences, and implications for the Regional Haze Rule
}

\author{
Rokjin J. Park ${ }^{\mathrm{a}, *}$, Daniel J. Jacob ${ }^{\mathrm{a}}$, Naresh Kumar ${ }^{\mathrm{b}}$, Robert M. Yantosca ${ }^{\mathrm{a}}$ \\ ${ }^{a}$ Division of Engineering and Applied Sciences and Department of Earth \& Planetary Sciences, Harvard University, \\ Cambridge, MA 02138, USA \\ ${ }^{\mathrm{b}}$ Electric Power Research Institute, Palo Alto, CA 94303, USA
}

Received 23 December 2005; received in revised form 14 March 2006; accepted 21 April 2006

\begin{abstract}
The Regional Haze Rule of the US Environmental Protection Agency mandates reduction in US anthropogenic emissions to achieve linear improvement of visibility in wilderness areas over the 2004-18 period toward an endpoint of natural visibility conditions by 2064 . Linear improvement is to apply to the mean visibility degradation on the statistically $20 \%$ worst days, measured as a Haze Index in units of deciviews (log of aerosol extinction). We use a global chemical transport model (GEOS-Chem) with $1^{\circ} \times 1^{\circ}$ horizontal resolution to simulate present-day visibility statistics in the USA, compare them to observations from the Interagency Monitoring of Protected Visual Environments (IMPROVE) surface network, and provide natural and background visibility statistics for application of the Regional Haze Rule. Background is defined by suppression of US anthropogenic emissions but allowance for present-day foreign emissions and associated import of pollution. Our model is highly successful at reproducing the observed variability of visibility statistics for present-day conditions, including the low tail of the frequency distribution that is most representative of natural or background conditions. We find considerable spatial and temporal variability in natural visibility over the USA, especially due to fires in the west. A major uncertainty in estimating natural visibility is the sensitivity of biogenic organic aerosol formation to the availability of preexisting anthropogenic aerosol. Background visibility is more variable than natural visibility and the $20 \%$ worst days show large contributions from Canadian and Mexican pollution. Asian pollution, while degrading mean background visibility, is relatively less important on the worst days. Recognizing the influence of uncontrollable transboundary pollution in the Regional Haze Rule would substantially decrease the schedule of emission reductions required in the 2004-18 implementation phase. Meaningful application of the Rule in the future will require projections of future trends in foreign anthropogenic emissions, wildfire frequency, and climate variables.
\end{abstract}

(C) 2006 Elsevier Ltd. All rights reserved.

Keywords: Aerosols; Regional Haze Rule; Visibility degradation; Transboundary pollution transport; IMPROVE

\footnotetext{
*Corresponding author. Tel.: + 16174964676 ; fax: +16174954551 .

E-mail address: rpark@fas.harvard.edu (R.J. Park).
}

\section{Introduction}

National parks and other natural areas in the USA suffer significant visibility degradation from 
anthropogenic aerosols (Malm et al., 2000). Although domestic sources are important, we have previously shown (Park et al., 2004) that transboundary transport of anthropogenic aerosols emitted outside the USA limits the potential for these areas to achieve natural visibility conditions as sought by the Regional Haze Rule (RHR) of the US Environmental Protection Agency (US EPA, 2003). Transboundary pollution includes contributions from Canada and Mexico, but also from Asia (Jaffe et al., 1999, 2003; Bertschi et al., 2004).

Our previous work (Park et al., 2004) used a 3-D global chemical transport model (Goddard Earth Observing System [GEOS]-Chem) with $2^{\circ} \times 2.5^{\circ}$ horizontal resolution to make mean national estimates of natural and transboundary pollution contributions to aerosol concentrations in the USA. It showed the importance of accounting for transboundary pollution in the application of the RHR. However, it did not provide site-by-site temporal visbility statistics of specific pertinence to the Rule, nor did it use these statistics to evaluate the ability of the model to describe the range of visibility conditions observed in the USA. We do so here with a GEOS-Chem simulation featuring finer $1^{\circ} \times 1^{\circ}$ horizontal resolution and improved representation of aerosol sources. We use this simulation to (1) revise our previous estimates of natural and transboundary pollution contributions to visibility degradation, (2) evaluate the ability of the model to reproduce the observed spatio-temporal variability of visibility across the USA, and (3) provide site-bysite model statistics of natural visibility and background visibility (allowing for transboundary pollution) for application of the RHR.

\section{The RHR}

The US EPA RHR mandates a schedule of increasing emission controls to improve visibility in Federal Class I areas (national parks and other wilderness areas) in the USA. Individual states must achieve linear decrease in visibility degradation for their Federal Class I areas over the 2004-18 period ("phase 1"), with a slope based on an aspirational endpoint of "natural visibility conditions" by 2064. Visibility degradation is measured as a Haze Index $(\mathrm{HI})$ in units of deciviews $(d v)$ :

$\mathrm{HI}=10 \ln \left(b_{\mathrm{ext}} / 10\right)$,

where $b_{\text {ext }}$ is atmospheric light extinction in unit of inverse megameter $\left(\mathrm{Mm}^{-1}\right)$. The EPA recommends the following formula to estimate $b_{\text {ext }}$ using dry mass aerosol concentrations of ammonium sulfate $\left(\left(\mathrm{NH}_{4}\right)_{2} \mathrm{SO}_{4}\right)$, ammonium nitrate $\left(\mathrm{NH}_{4} \mathrm{NO}_{3}\right)$, organic carbon mass (OMC), elemental carbon (EC), soil dust, and coarse mass $(\mathrm{CM})$ :

$$
\begin{aligned}
b_{\text {ext }}= & 3 f(\mathrm{RH})\left(\left[\left(\mathrm{NH}_{4}\right) 2 \mathrm{SO}_{4}\right]+\left[\mathrm{NH}_{4} \mathrm{NO}_{3}\right]\right) \\
& +4[\mathrm{OMC}]+10[\mathrm{EC}]+[\text { soil }]+0.6[\mathrm{CM}]+10,
\end{aligned}
$$

where aerosol concentrations are in units of $\mu \mathrm{g} \mathrm{m}^{-3}$. The OMC concentration includes the noncarbon mass attached to organic carbon (OC) aerosol and is derived by multiplying measured OC concentrations by a factor of 1.4 (Malm et al., 1994). The multiplication factors for the aerosol concentrations are typical extinction efficiencies. $f(\mathrm{RH})$ is a hygroscopic growth factor function of relative humidity (RH) applied to sulfate and nitrate aerosols; recommended climatological values for each of the Federal Class I areas are given in the RHR document (US EPA, 2003). Typical values for $f(\mathrm{RH})$ are 3 in the east and 2 in the west. The constant of $10 \mathrm{Mm}^{-1}$ in Eq. (2) describes the scattering by air molecules and is such that an aerosol-free atmosphere would have a HI of zero. The term "soil" in Eq. (2) is the fine component of soil dust (diameter $<2.5 \mu \mathrm{m}$ ) and "CM" is the total mass of particles with diameter $>2.5 \mu \mathrm{m}$, mostly contributed by dust and sea salt. A contribution of fine sea salt aerosol to the light extinction is not accounted for in Eq. (2) but can be important in coastal regions (Ames and Malm, 2001b; Ying et al., 2004; Tombach and Brewer, 2005).

The Interagency Monitoring of Protected Visual Environments (IMPROVE) network of sites was initiated in 1987 to measure visibility degradation in Federal Class I areas (Malm et al., 1994). Its observations can be used to enforce the compliance requirements for the RHR. As of 2002 it included 156 sites in the USA, with a greater density in the west. The data consist of $24-\mathrm{h}$ speciated aerosol concentrations measured every third day including sulfate, nitrate, EC, OC, fine soil, and CM. The data can be used with Eqs. (1) and (2) to derive the local HI. The resulting visibility statistics obtained for 2000-04 define the "baseline" (present-day) visibility for application of the RHR.

Starting from this present-day baseline, one has to define a natural visibility endpoint for 2064 in order to determine the required linear improvement in visibility over phase 1 of the RHR (2004-18). US 
EPA (2003) provides default estimates of annual average natural concentrations for the individual aerosol components in Eq (2), separately for the western and eastern USA, to derive "natural visibility conditions" for application of the RHR. These default natural concentrations can be superseded by site-specific values if better information is available.

Linear improvement of visibility degradation under the RHR uses as a metric the mean HI for the $20 \%$ worst visibility days as determined from 5 year statistics. To derive this metric for natural visibility conditions, EPA recommends a default approach of taking the 90th percentile of a normal distribution of daily $\mathrm{HI}$ values with standard deviations of 2 and 3 in the western and eastern USA, respectively (Ames and Malm, 2001a). The 90th percentile slightly underestimates the mean of $20 \%$ worst visibility days (Tombach and Brewer, 2005) and we therefore use the 92nd percentile (Ryan, 2004).

The importance of the 2064 natural visibility endpoint for implementing the current round (2004-18) of emission reductions under the RHR was pointed out by Park et al. (2004). Because visibility degradation is a logarithmic function of aerosol extinction (Eq. (1)), a linear improvement of visibility requires an exponential decrease of aerosol concentrations, and the magnitude of this decrease is sensitive to the choice of the 2064 visibility endpoint value. In addition, since the RHR has no provision for engaging other countries in reducing emissions, transboundary pollution influences will increase the burden for reducing domestic emissions to meet the requirements of the RHR. We have previously proposed that "background" visibility, allowing for transboundary pollution, is a more sensible 2064 endpoint. In any case, better quantitative understanding of natural and background visibility is needed.

\section{Model description}

We use the GEOS-Chem global chemical transport model (CTM) of coupled aerosol-oxidant chemistry (Park et al., 2004) to conduct fullyear simulations for 2001. The GEOS-Chem model (version 7.02, http://www-as.harvard.edu/ chemistry/trop/geos) uses assimilated meteorological data from the NASA GEOS-3 including winds, convective mass fluxes, mixed layer depths, temperature, clouds, precipitation, and surface proper- ties. Meteorological data for 2001 are available with 6-h temporal resolution (3-h for surface variables and mixing depths), $1^{\circ}$ latitude by $1^{\circ}$ longitude $\left(1^{\circ} \times 1^{\circ}\right)$ horizontal resolution, and 48 sigma vertical layers. The lowest model levels are centered at approximately 10, 50, 100, 200, 400, 600, 900, 1200, and $1700 \mathrm{~m}$ above the local surface. All simulations here were conducted using a nested continentalscale version of GEOS-Chem (Wang et al., 2004) with $1^{\circ} \times 1^{\circ}$ horizontal resolution over North America and adjacent oceans $\left(140-40^{\circ} \mathrm{W}\right.$, $\left.10-60^{\circ} \mathrm{N}\right)$ and $4^{\circ} \times 5^{\circ}$ horizontal resolution for the rest of the world.

Park et al. (2003, 2004) previously presented GEOS-Chem aerosol simulations to estimate natural and background concentrations in the USA. These simulations were conducted for 1998 and 2001 with $2^{\circ} \times 2.5^{\circ}$ horizontal resolution. They included OC, EC, and sulfate-nitrate-ammonium (SNA) aerosols. The aerosol simulations in GEOSChem are coupled to oxidant chemistry through formation of sulfate, nitrate, and secondary organic aerosols (SOA), $\mathrm{HNO}_{3}(\mathrm{~g}) / \mathrm{NO}_{3}^{-}$partitioning of total inorganic nitrate, heterogeneous chemistry (Jacob, 2000), and aerosol effects on photolysis rates (Martin et al., 2003). The model includes primary emissions of EC and $\mathrm{OC}$ in hydrophobic forms, with an e-folding time of 1 day for conversion to hydrophilic forms subject to wet deposition (Cooke et al., 1999; Chin et al., 2002; Park et al., 2005). SOA is assumed hydrophilic. Wet deposition follows the scheme of Liu et al. (2001). Dry deposition follows a standard resistance-in-series model (Wesely, 1989), implemented as described by Wang et al. (1998).

We use 1999-2000 global anthropogenic emission inventories for sulfur and $\mathrm{NO}_{x}$ (Park et al., 2004). North American emissions are updated from those used by Park et al. (2004) as follows. In the USA we use the US EPA National Emission Inventory for 1999 (NEI99, http://www.epa.gov/ttn/chief/net/ 1999inventory.html). The contiguous US sulfur and $\mathrm{NO}_{x}$ emissions are $9.0 \mathrm{Tg} \mathrm{Syr}^{-1}$ and 6.2 $\mathrm{Tg} \mathrm{Nyr}^{-1}$. We updated Canadian sulfur emissions using EMEP emission estimates for 2001 (Vestreng et. al., 2004) and Mexican sulfur emissions using the BRAVO emission inventory for 1999 (Kuhns et al., 2005). Our Canadian and Mexican sulfur emissions are 1.2 and $1.3 \mathrm{Tg} \mathrm{Syr}^{-1}$, respectively and are lower than those used in Park et al. (2004) (2.0 and 1.9 $\mathrm{Tg} \mathrm{S} \mathrm{yr}^{-1}$ ). In addition, we include here a global $\mathrm{SO}_{2}$ emission of $4.2 \mathrm{Tg} \mathrm{S} \mathrm{yr}^{-1}$ from ships, following the 
spatially distributed inventory of Corbett et al. (1999).

Our global anthropogenic ammonia emissions are from Bouwman et al. (1997), with seasonal variation described by Park et al. (2004). The most important ammonia source is domesticated animals and has an exponential dependence on temperature (Aneja et al., 2000). The US emission of ammonia in the NEI99 inventory $\left(3.6 \mathrm{Tg} \mathrm{N} \mathrm{yr}^{-1}\right)$ is known to be too high (Gilliland et al., 2003). Therefore we retained the US emission inventory of Park et al. (2004) (2.2 $\left.\mathrm{Tg} \mathrm{N} \mathrm{yr}^{-1}\right)$.

We use the global anthropogenic (fuel) emissions

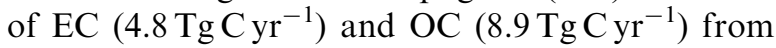
the gridded annual Bond et al. (2004) inventory for 1996 of which US anthropogenic EC and OC emissions are 0.38 and $0.52 \mathrm{TgC} \mathrm{yr}^{-1}$, respectively. The resulting OC simulation underestimates by factor of 2 or more the observed concentrations in US surface air, including in winter when SOA is low. Therefore we supersede the anthropogenic OC inventory in the USA with the emission estimate of 1.4 $\mathrm{Tg} \mathrm{C} \mathrm{yr}^{-1}$ by Park et al. (2003), obtained by a multivariate fit to mean $\mathrm{OC}$ aerosol concentrations at IMPROVE sites in 1998.

Natural emissions of SNA and carbonaceous aerosols include volcanoes, lightning, the biosphere (terrestrial and marine), and biomass burning. These sources are as given by Park et al. (2004). We use a climatological biomass burning emission inventory with $1^{\circ} \times 1^{\circ}$ spatial resolution and monthly temporal resolution (Duncan et al., 2003), and emission factors from Andreae and Merlet (2001). For the USA, the Duncan et al. (2003) inventory includes emissions only from wildfires and is therefore appropriately viewed as natural. We also assume here a direct biogenic OC aerosol source amounting to $1 \%$ of monoterpene emission to account for evidence of fast nucleation in forested areas (Marti et al., 1997; O'Dowd et al., 2002; Kavouras and Stephanou, 2002).

The chemical scheme is that of Park et al. (2003, 2004) but with two significant improvements. SOA formation now follows the scheme of Chung and Seinfeld (2002), which involves oxidation of several classes of biogenic hydrocarbons and gas-aerosol partitioning of the semi-volatile products as a function of local temperature and pre-existing $\mathrm{OC}$ mass concentration. The reaction probability $\left(\gamma_{\mathrm{N} 2 \mathrm{O} 5}\right)$ for $\mathrm{N}_{2} \mathrm{O}_{5}$ uptake and hydrolysis in aerosols is now as described by Evans and Jacob (2005) as a function of local aerosol composition, temperature, and RH. This yields a much lower global mean $\gamma_{\mathrm{N} 2 \mathrm{O} 5}(0.02)$ than previous used $(0.1)$.

Finally, an algorithmic improvement relative to Park et al. $(2003,2004)$ is to apply surface emissions and dry deposition to the GEOS-diagnosed mixed layer column rather than to the lowest model layer. This was introduced to correct for the effect of 1-h time splitting between the transport and chemical operators (the latter including emissions and dry deposition), when dealing with a very shallow lowest model layer (only 10-m deep in GEOS-3). The effect is significant for fast-depositing gases such as $\mathrm{HNO}_{3}$ and $\mathrm{NH}_{3}$.

We conducted four different simulations for 2001 including one standard simulation as described above, and three sensitivity simulations excluding anthropogenic emissions (1) globally, (2) in the USA, and (3) in North America. From these we quantify the influences of natural, transboundary, and intercontinental pollution sources on aerosol concentrations in the USA. All simulations were carried out as follows. We first conducted a global simulation with $4^{\circ} \times 5^{\circ}$ horizontal resolution. Results were archived to provide boundary conditions for the $1^{\circ} \times 1^{\circ}$ nested model simulation (Wang et al., $2004)$ over the North American domain $\left(140-40^{\circ} \mathrm{W}\right.$, $\left.10-60^{\circ} \mathrm{N}\right)$. All simulations were initialized on September 1, 2000 and conducted for 16 months. The first four months were used to achieve proper initialization, and we focus our attention on the following 12 months.

\section{Spatial and seasonal patterns of aerosol concentrations in the USA}

Previous model evaluations of spatial and seasonal patterns of aerosol concentrations in the USA have been presented by Park et al. (2003) for EC and OC, and by Park et al. (2004) for SNA. The present simulation includes a number of objective improvements and higher resolution, as described in Section 3. We examine here the effects of these improvements on the ability of the model to reproduce observations.

Fig. 1 compares simulated and observed annual mean sulfate and nitrate concentrations at the 135 IMPROVE sites in the USA for the year 2001. Ammonium concentrations are measured only at a few IMPROVE sites and we use instead observations at the 79 Clean Air Status and Trends Network (CASTNET) non-urban sites (Lavery et al., 2002). The highest sulfate concentrations are 

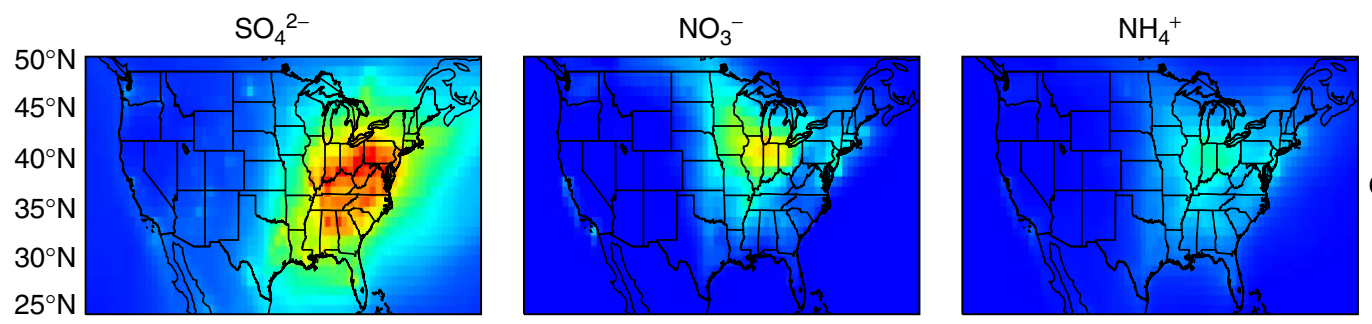

GEOS - Chem
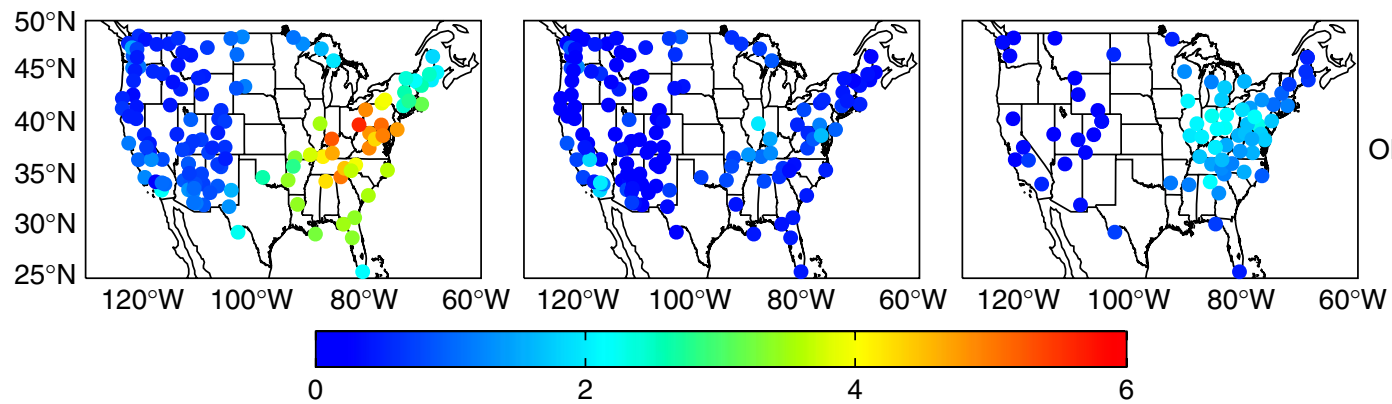

OBSERVATIONS

$\left[\mu \mathrm{g} \mathrm{m}^{-3}\right]$

Fig. 1. Annual mean concentrations of sulfate-nitrate-ammonium (SNA) aerosols in surface air over the USA in 2001. Results from the GEOS-Chem model are compared to observations from the IMPROVE network for sulfate and nitrate, and the CASTNET network for ammonium.

in the industrial Midwest due to coal-fired power plants. Maximum ammonium concentrations are slightly to the west, reflecting the combined effects of agricultural ammonia emissions and the availability of sulfate and nitrate for ammonium formation. The spatial distribution of aerosol nitrate is similar to that of ammonium and reflects the general limitation of ammonium nitrate formation by the availability of ammonia (Park et al., 2004).

Fig. 2 shows scatterplots of simulated vs. observed annual and seasonal sulfate, nitrate, and ammonium concentrations in the same form as in Park et al. (2004). Regression lines are computed here and elsewhere with the reduced major axis method (Hirsch and Gilroy, 1984). The coefficient of determination $\left(R^{2}\right)$ and linear regressions are shown inset. Sulfate in the model reproduces the spatial variability in the observations both on an annual basis $\left(R^{2}=0.92\right)$ and on a seasonal basis $\left(R^{2}=0.83-0.90\right)$. These values are similar to those obtained by Park et al. (2004) with $2^{\circ} \times 2.5^{\circ}$ spatial resolution. Regressions slopes are 1.1 for annual means and $0.84-1.31$ for seasonal means. These values are slightly higher than in Park et al. (2004).

The model reproduces the variability of observed ammonium concentrations, both in an annual mean sense $\left(R^{2}=0.88\right)$ and in different seasons $\left(R^{2}=0.82-0.85\right)$ with no apparent bias in an annual mean concentrations (slope $=1.1)$. The $R^{2}$ values are consistent with those in the Park et al. (2004) simulation but the regression slopes are closer to unity because of the improved treatment of ammonia dry deposition. The $50 \%$ model overestimate in fall likely reflects a strong seasonal decrease in emissions (Gilliland et al., 2003) that is not sufficiently captured in our temperature-dependent parameterization.

Simulated aerosol nitrate concentrations are too high by $30 \%$ on average (Fig. 2), which represents a major improvement over Park et al. (2004) where the overestimate was a factor of 2. Improved simulation of ammonia, better treatment of dry deposition, and slower $\mathrm{N}_{2} \mathrm{O}_{5}$ hydrolysis appear to be responsible. The $R^{2}$ is highest in winter $(0.44)$ when concentrations are maximum. The model shows no skill in summer $\left(R^{2}=0.06\right)$ but concentrations are then very low.

Fig. 3 compares simulated and observed annual mean EC and OC concentrations at the 135 IMPROVE sites. EC concentrations are higher in the east than the west due to diesel and biofuel emissions. OC concentrations are highest in the southeast because of biogenic SOA. The model shows a strong maximum in Alabama and Georgia but there is not enough IMPROVE data coverage to evaluate this feature. We further compared model 

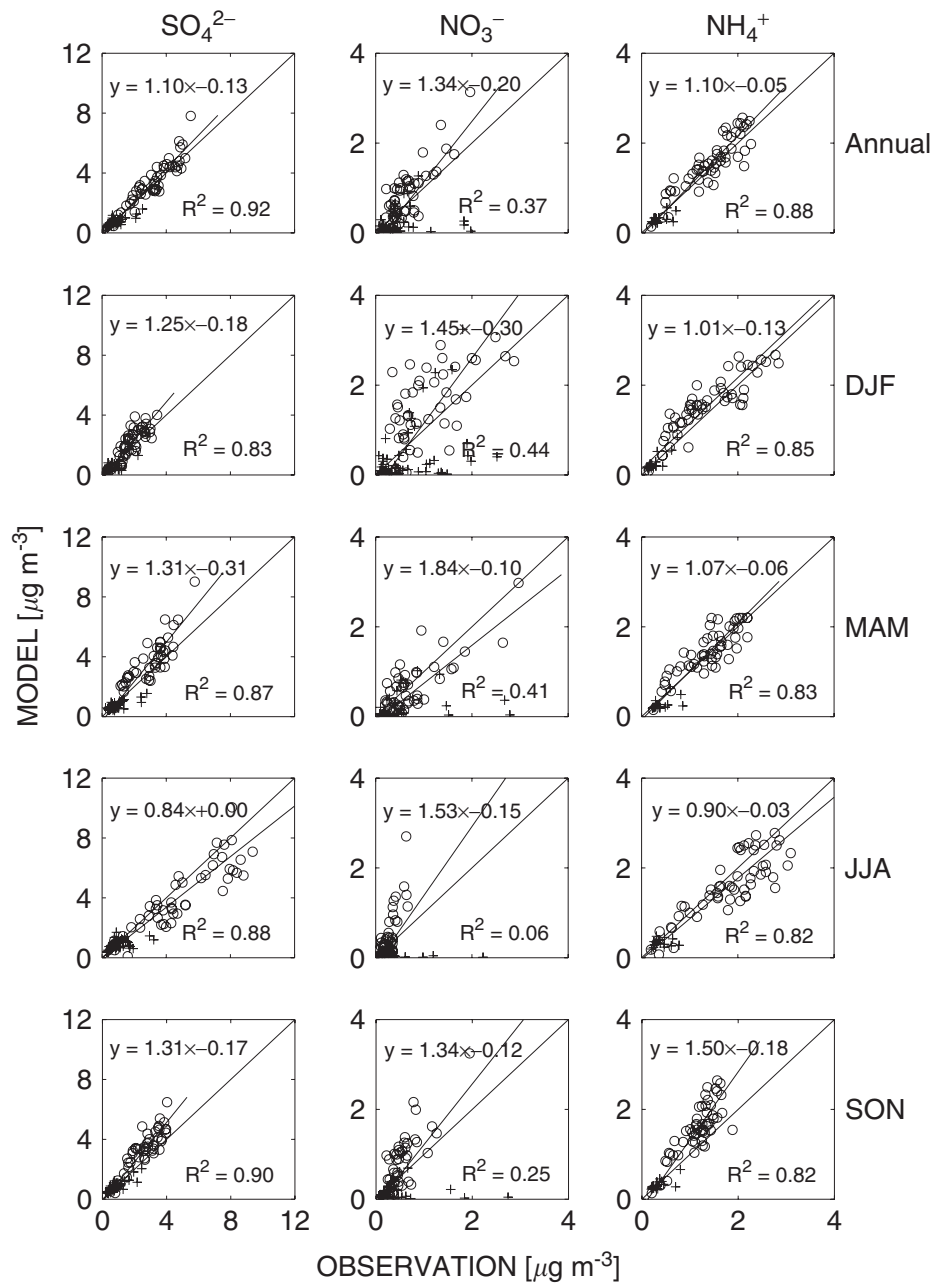

Fig. 2. Scatterplots of simulated versus observed sulfate (left) and nitrate (middle) concentrations for the ensemble of the IMPROVE sites, and ammonium concentrations (right) for the CASTNET sites. Values are annual means (top panels) and seasonal means for 2001. Different symbols are used for sites in the western (pluses) and eastern (circles) USA (separated at $95^{\circ} \mathrm{W}$ ). Reduced major axis regressions for the ensemble of the data (thick lines) are shown along with the regression equations and $R^{2}$. The $y=x$ relationships (thin lines) are also shown.

results with observations at three rural sites (Centreville, Alabama; Yorkville, Georgia, and Oak Grove, MS, USA) from the SouthEastern Aerosol Research and Characterization Study experiment (SEARCH) (Hansen et al., 2003). The simulated OC concentrations in summer at those three sites are $3.3,2.0$, and $2.4 \mu \mathrm{g} \mathrm{m}^{-3}$, respectively, which are consistent with the observations of 3.0 , 2.6, and $3.4 \mu \mathrm{g} \mathrm{m}^{-3}$.

Fig. 4 shows scatterplots of simulated vs. observed annual and seasonal EC and OC concentrations. The simulated EC has some success in reproducing the variability of observations for annual $\left(R^{2}=0.57\right)$ and seasonal mean concentra- tions $\left(R^{2}=0.37-0.54\right)$. The model is about $15 \%$ lower than the observations. The model has similar success in explaining the variability of observed OC concentrations on an annual mean basis $\left(R^{2}=0.49\right)$ and a seasonal mean basis $\left(R^{2}=0.27-0.52\right)$, with no apparent biases. The lack of bias for OC reflects in part the previous adjustment of primary emissions to match IMPROVE observations for 1998 (Park et al., 2003). For both EC and OC, the weakest correlations are found in summer because of local fire influences in the west (mostly two California sites) that are not properly described in our climatological fire inventory. The $R^{2}$ values for EC and $\mathrm{OC}$ were generally better in the Park et al. 

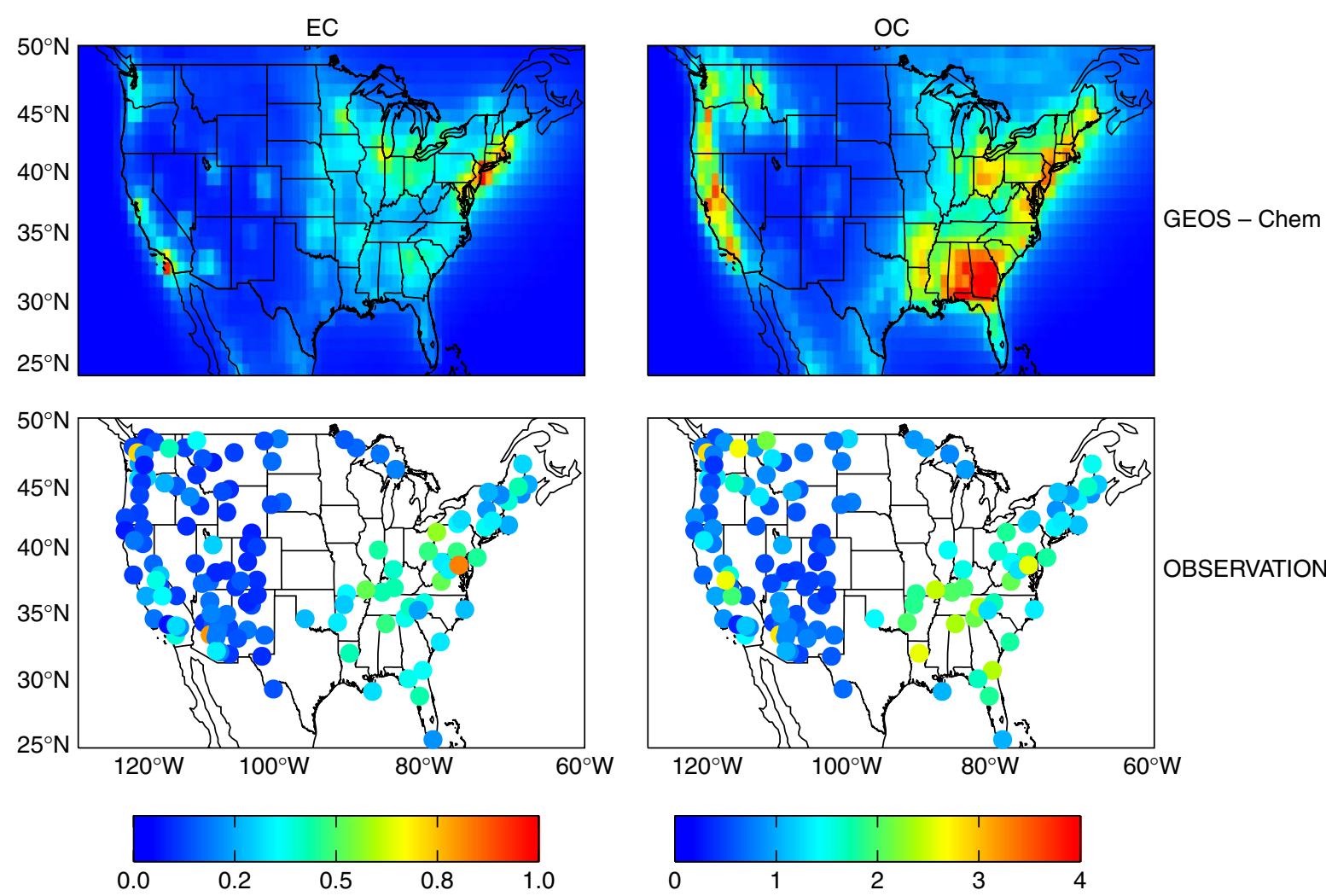

$\left[\mu \mathrm{g} \mathrm{m}^{-3}\right]$

Fig. 3. Annual mean concentrations of elemental carbon (EC) and organic carbon (OC) aerosols in surface air over the USA in 2001. Results from the GEOS-Chem model are compared to the observations from the IMPROVE network.

(2003) work, which used a year-specific biomass burning emission for 1998. However, climatological emissions are needed here to provide mean visibility statistics of relevance to the RHR.

\section{Present-day (baseline) visibility statistics}

In this section we use model results to compute present-day visibility degradation for the USA and compare with IMPROVE observations. We apply Eqs. (1) and (2) to the observed and simulated daily aerosol concentrations of sulfate, nitrate, EC, and OMC for 2001. Eq. (2) also requires information on fine soil dust and CM concentrations but these are not simulated here. We therefore apply observed soil dust and CM concentrations in 2001 to the visibility calculations both for the model and for the observations. We sample model results every third day in accordance with the timing of IMPROVE measurements and focus our analysis on the 109 sites with 80 or more daily observations available for the year 2001 .
Fig. 5 compares the observed and simulated means and standard deviations of visibility degradation (HI) in deciviews at the IMPROVE sites. Sulfate accounts for more than $60 \%$ of total aerosol extinction in the east and for $30-40 \%$ in the west (Malm et al., 2000). OC accounts for $\sim 30 \%$ of total aerosol extinction in the west but only $\sim 10 \%$ in the east (Malm et al., 2000), reflecting weak hygroscopic growth (Malm and Day, 2001; Malm et al., 2003). In southern California, aerosol nitrate is the single largest contributor to aerosol extinction. The model reproduces successfully the observed spatial pattern of mean visibility degradation in Fig. 5 with high $R^{2}(0.88)$ and no significant bias (regression slope $=1.1)$.

Standard deviations in Fig. 5 measure the temporal variability of visibility degradation at individual sites. Values are highest in the northeast due to the synoptic contrast between polluted southwesterly flow with high sulfate concentrations from the Midwest and clean flow from the northwest. The observed spatial patterns of standard 

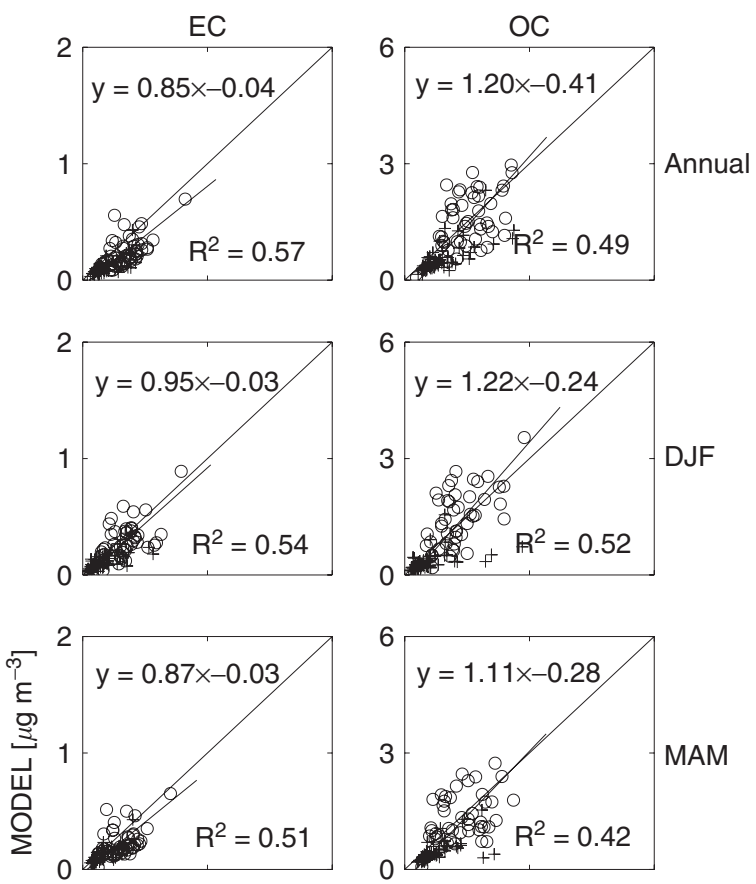

MAM
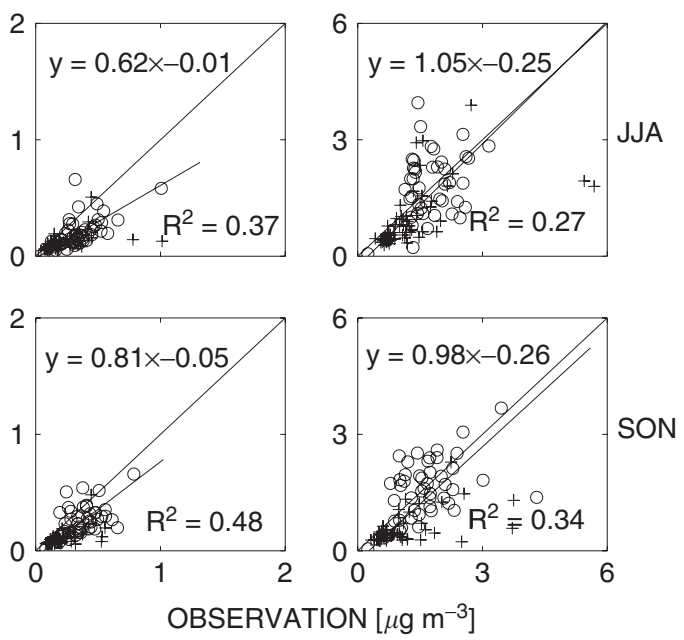

Fig. 4. Scatterplots of simulated versus observed EC (left) and OC (right) concentrations at the IMPROVE sites. Values are annual means (top panels) and seasonal means for 2001. Different symbols are used for sites in the western (pluses) and eastern (circles) USA (separated at $95^{\circ} \mathrm{W}$ ). Reduced major axis regressions for the ensemble of the data (thick lines) are shown along with the regression equations and $R^{2}$. The $y=x$ relationships (thin lines) are also shown.

deviations are again captured well by the model $\left(R^{2}=0.66\right.$, regression slope $\left.=1.1\right)$.

Fig. 6 compares cumulative probability distributions of simulated and observed daily $\mathrm{HI}$ at IMPROVE sites representative of different regions and diagnosing the range of model discrepancies identified in our analysis. The distributions are generally close to normal, as indicated by a straight line, and reflecting the typical log-normal distribution of aerosol concentrations (Whitby, 1978). High outliers at Yellowstone National Park are due to local wildfires. Overall, we find that the model has considerable success in reproducing not only the means but also the tails of the distributions. The low tails are of particular importance in lending confidence in the ability of the model to simulate background conditions. The IMPROVE site where the model shows large discrepancy with observations for this low tail is Chassahawitzka in Florida (Fig. 6) where model precipitation is excessive.

Fig. 6 also describes the main regional patterns of model errors. The model overestimates visibility degradation at some northwestern sites, as illustrated by the Three Sisters site in Oregon. This appears due to excessive biogenic SOA in the model, resulting from regional overestimate of vegetative monoterpene emission in the Guenther et al. (1995) inventory used to drive the model. The more recent MEGAN biogenic emission inventory (Guenther et al., 2006) indicates substantially lower monoterpene emissions in the northwestern USA and Canada.

The model underestimates visibility degradation at Joshua Tree in Southern California because of low nitrate aerosol concentrations. Previous studies (Kleeman et al., 1999; Hughes et al., 2000, 2002; Singh et al., 2002; Neuman et al., 2003; Held et al., 2004) have shown a dominant contribution of ammonium nitrate to observed fine aerosol concentrations in Southern California, driven by local ammonia emission from animal farms (Battye et al., 2003). Our ammonia emission inventory may not adequately capture this source.

The model is also somewhat low at the Big Bend site in Texas, where most of the observed visibility degradation is due to sulfate and includes a major contribution from Mexican emissions (Pitchford et al., 2004). Kuhns et al. (2005) found that the BRAVO Mexican $\mathrm{SO}_{2}$ emission inventory used in our work is lower by $30 \%$ than the 1999 Mexican National Emission Inventory (NEI) (ERG, 2003).

\section{Background aerosol concentrations in the USA}

We revise here our previously estimated natural and background aerosol concentrations in the western and eastern USA for application of the RHR (Park et al., 2003, 2004), and examine in more 

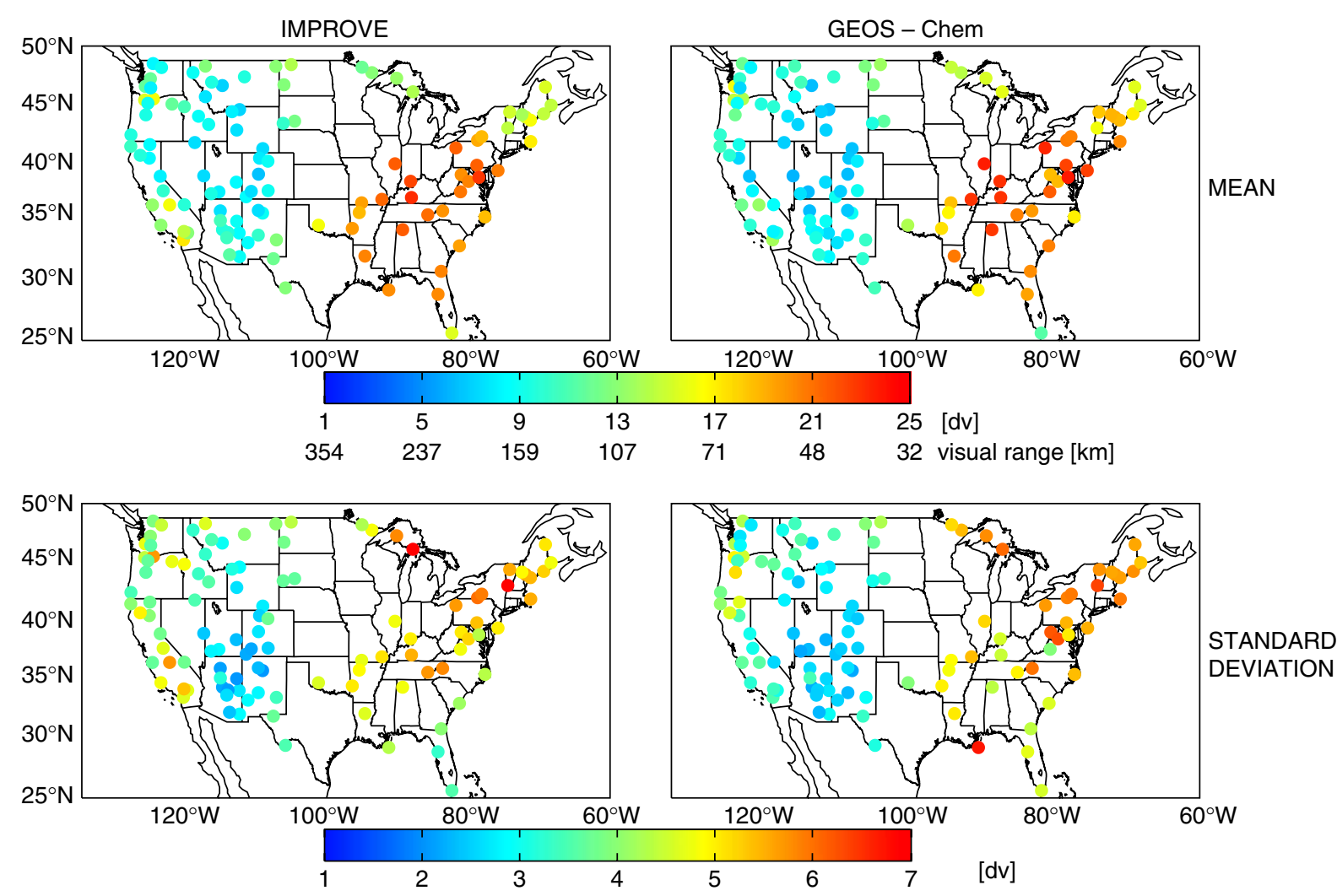

Fig. 5. Observed and simulated means and standard deviations of daily visibility degradation (Haze Index) in deciviews for the year 2001. Values are computed by applying Eqs. (1) and (2) to daily concentrations of aerosol sulfate, nitrate, EC, OMC, fine soil, and coarse mass at the IMPROVE sites. The corresponding visual range is also shown (Pitchford and Malm, 1994).

detail their spatial distributions. "Background" refers to the concentrations that would be present in the absence of US anthropogenic emissions, and includes contributions from both natural and transboundary pollution sources.

Fig. 7 shows annual mean natural and background concentrations of SNA aerosols in surface air from the sensitivity simulations with anthropogenic emissions shut off globally and in the USA, respectively. Natural concentrations for SNA aerosols are low (the highest contribution is marine sulfate from oxidation of DMS) and are distributed uniformly over the USA. Background SNA concentrations are many-fold higher than natural and show strong spatial patterns, reflecting transboundary pollution influences mostly from Canada and Mexico.

Fig. 8 shows natural and background concentrations for OC (concentrations of EC are much lower and relatively unimportant for visibility degradation). Two limiting cases are shown: (1) a low limit where production of biogenic SOA is reduced following Chung and Seinfeld (2002) due to reduced supply of primary anthropogenic OC aerosols; (2) a high limit where biogenic SOA is the same as in the standard baseline calculation, i.e., assuming that SOA formation is not limited by the supply of preexisting aerosol. The difference between the two limits is large, illustrating the current uncertainty regarding the sensitivity of biogenic SOA formation to anthropogenic emissions. Highest natural OC concentrations are found in the northwest in the low limit, reflecting emissions from fires (Park et al., 2003). In the high limit, a second maximum is found in the southeast due to biogenic SOA. For subsequent analyses we will use the high limit simulation. Unlike for SNA, transboundary pollution influences are small relative to the natural sources, as discussed previously by Park et al. (2003).

Natural and background aerosol concentrations from the model are summarized in Table 1 as annual averages for the ensemble of IMPROVE sites in the western and eastern USA partitioned at 

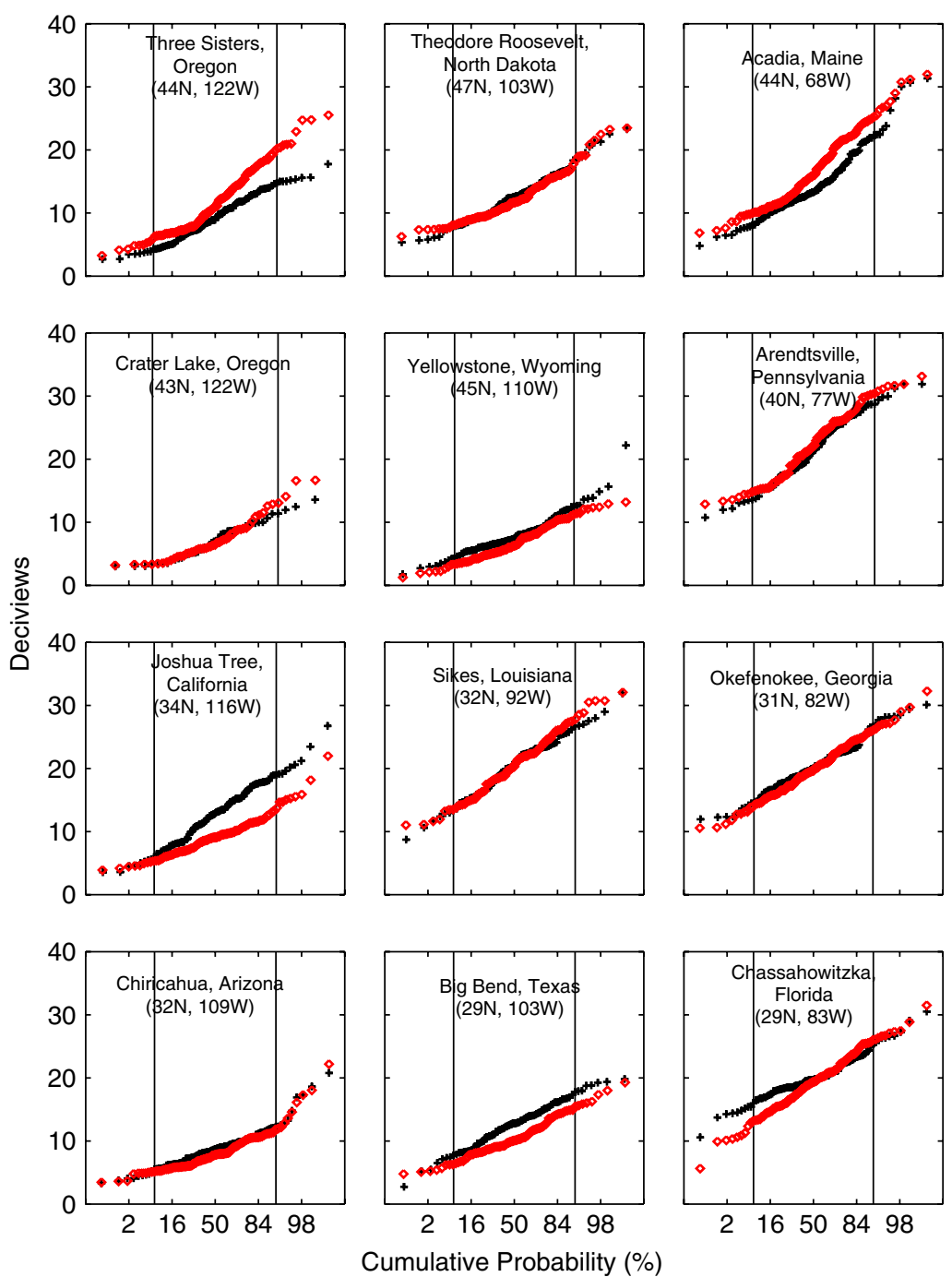

Fig. 6. Cumulative probability distributions of daily visibility degradation (Haze Index) in deciviews at representative IMPROVE sites in 2001. Black pluses indicate the observations and red diamonds represent the model values. The cumulative probability distribution is plotted on a standard normal probability scale such that a normal distribution would be a straight line. Thin vertical lines indicate 8 th and 92nd percentiles.

$95^{\circ} \mathrm{W}$. The EPA default annual average natural concentrations are also shown. A previous version of Table 1 based on our earlier model simulations was presented by Park et al. (2004) and discussed there in terms of the implications for the RHR.

Background concentrations of ammonium sulfate are 0.50 and $0.86 \mu \mathrm{g} \mathrm{m}^{-3}$ in the western and eastern USA, several-fold higher than the EPA natural defaults because of the influence from transboundary pollution. These values are even higher than our previous estimates $(0.43$ in the west and 0.38 in the east) in Park et al. (2004), especially in the northeast because of more accurate resolution of Canadian emissions close to the border when the $1^{\circ} \times 1^{\circ}$ grid is used. We find that the transboundary pollution influence on sulfate is mostly from Canada and Mexico, but also includes a non-negligible component from the rest of the world, mainly from Asia and international ships. For ammonium nitrate we find background concentrations of 0.06 and $0.12 \mu \mathrm{g} \mathrm{m}^{-3}$ in the western and the eastern USA, respectively. These are an order of higher than our computed natural concentrations but comparable to the EPA natural default values.

Our natural and background OMC concentrations are roughly comparable with the EPA natural 

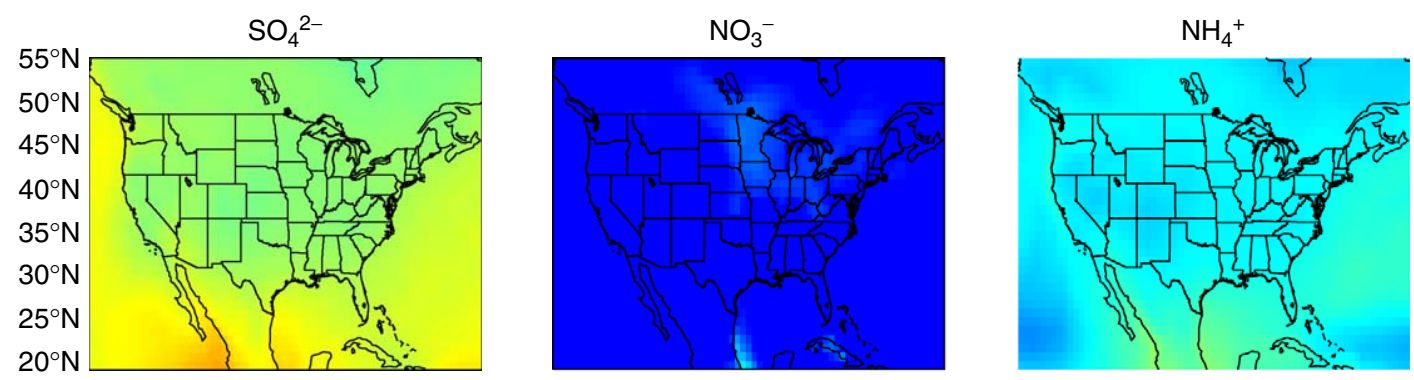

NATURAL
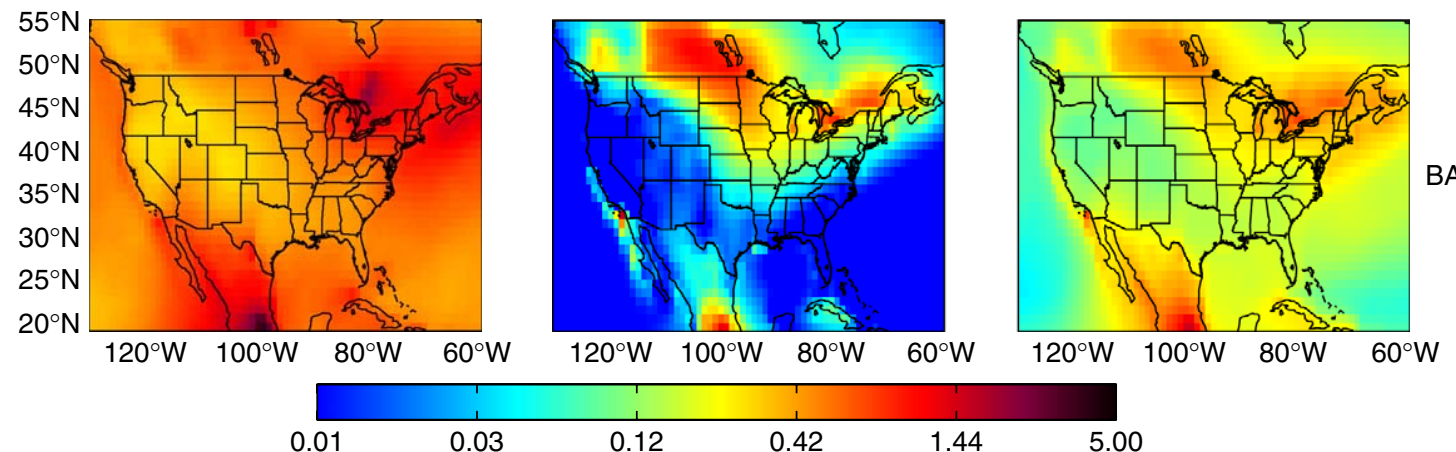

BACKGROUND

$\left[\mu \mathrm{g} \mathrm{m}^{-3}\right]$

Fig. 7. Natural and background concentrations of sulfate, nitrate, and ammonium aerosols in surface air. Values are annual means and are obtained from sensitivity simulations with global and US anthropogenic sources shut off, respectively.

default in the west. In the east, however, our estimates are much lower. This discrepancy has important implications for natural visibility calculations, as discussed in Section 7. Heald et al. (2005) recently reported $\mathrm{OC}$ aerosol concentrations averaging $4 \mu \mathrm{g} \mathrm{m}^{-3}$ STP in free tropospheric air $(2-7 \mathrm{~km})$ off the coast of Japan, 10-100 times higher than the corresponding values simulated by GEOS-Chem, and only weakly correlated with pollution indicators (CO, sulfate). Subsidence of free tropospheric air containing such elevated OC aerosol could have important implications for OC background concentrations in the USA, although the magnitude of the effect is not clear. OC concentrations observed in the USA are in general substantially less than $4 \mu \mathrm{g} \mathrm{m}^{-3}$ (Fig. 3).

\section{Variability in natural and background visibility}

The RHR uses as its metric the mean visibility degradation for the $20 \%$ worst visibility days. This metric applies to the 2064 natural visibility endpoint as well, and requires estimates of the temporal variability of natural visibility degradation. The RHR document (EPA, 2003) recommends using standard deviations of $2 \mathrm{dv}$ in the west and $3 \mathrm{dv}$ in the east for the frequency distribution of daily natural visibility degradation, based on the work of Ames and Malm (2001a). We evaluate here this recommendation by using our model results to derive temporal statistics of natural and background visibility at IMPROVE sites. The visibility calculations are as described in Section 5.

Fig. 9 shows the cumulative probability distributions of the simulated natural and background visibility degradation (HI) at the IMPROVE sites for which we previously discussed the baseline (present-day) visibility statistics (Fig. 6). Simulated standard deviations of natural visibility degradation at individual sites average $2.9 \mathrm{dv}$ in the west and 2.4 $\mathrm{dv}$ in the east, higher in the west because of fires, in contrast to the recommendation of the RHR document. Simulated standard deviations of background visibility degradation average $2.9 \mathrm{dv}$ for both the west and east. Actual standard deviations would be higher since the model uses climatological monthly mean fire emissions, as illustrated in Fig. 6 for Yellowstone National Park.

We use our model results to estimate natural and background visibility degradation averaged for the $20 \%$ worst days at the IMPROVE sites, and take these estimates to define the corresponding site-by- 

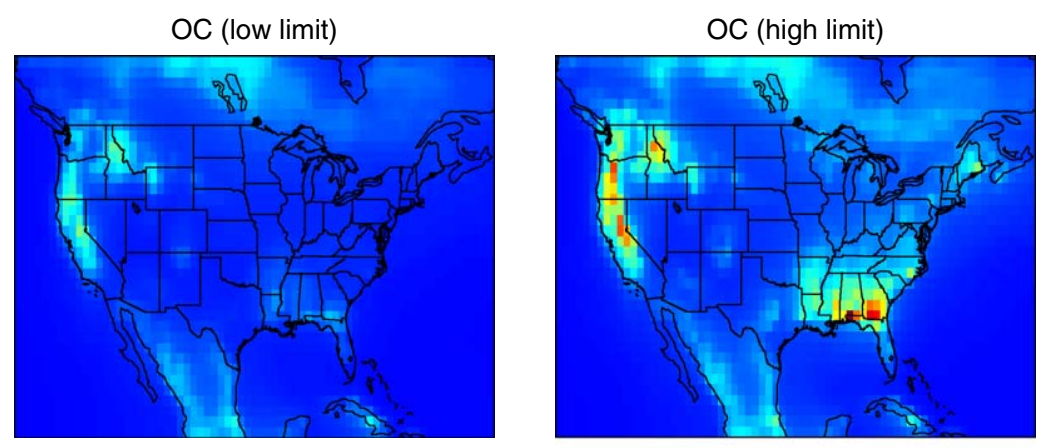

NATURAL
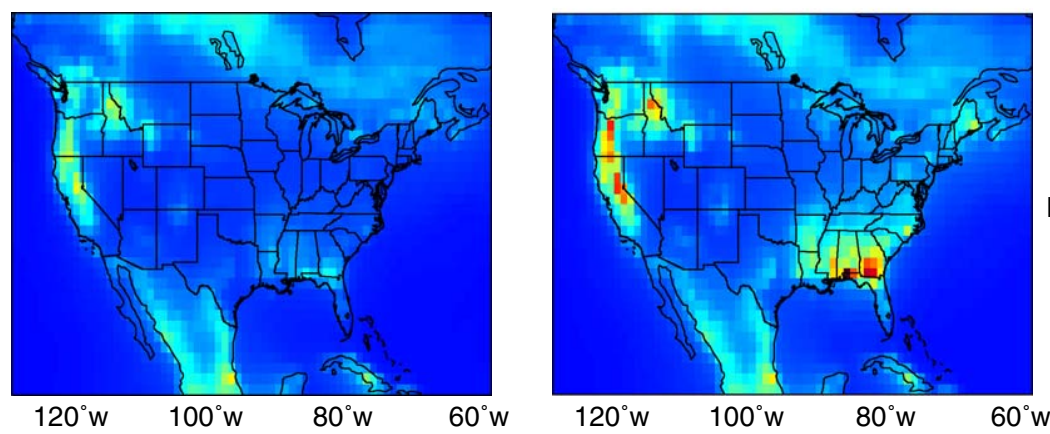

\section{BACKGROUND}

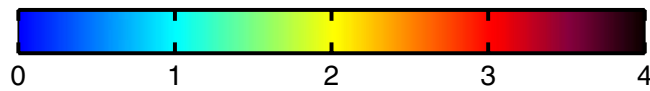

$\left[\mu \mathrm{g} \mathrm{m}^{-3}\right]$

Fig. 8. Same as in Fig. 7 but for organic carbon (OC) natural and background concentrations. The low limit accounts for reduction in biogenic SOA following Chung and Seinfeld (2002) due to a lower concentration of primary OC aerosol on which this biogenic SOA can condense. The high limit includes biogenic SOA from the standard baseline simulation, assuming that condensation of this SOA is not limited by the supply of preexisting aerosol.

Table 1

Background and natural aerosol concentrations in the USA ${ }^{\mathrm{a}}$

\begin{tabular}{|c|c|c|c|c|c|c|c|c|}
\hline & \multicolumn{2}{|c|}{ Ammonium sulfate ${ }^{b}$} & \multicolumn{2}{|c|}{ Ammonium nitrate } & \multicolumn{2}{|c|}{ Elemental carbon } & \multicolumn{2}{|c|}{ Organic carbon mass ${ }^{\mathrm{c}}$} \\
\hline & West & East & West & East & West & East & West & East \\
\hline Background & 0.50 & 0.86 & 0.06 & 0.12 & 0.04 & 0.03 & $0.54-0.68$ & $0.41-0.77$ \\
\hline Natural & 0.17 & 0.17 & 0.01 & 0.01 & 0.01 & 0.01 & $0.39-0.58$ & $0.22-0.65$ \\
\hline Transboundary pollution & 0.33 & 0.71 & 0.05 & 0.11 & 0.02 & 0.03 & 0.10 & 0.12 \\
\hline Canada \& Mexico & 0.22 & 0.53 & 0.04 & 0.09 & 0.01 & 0.02 & 0.08 & 0.10 \\
\hline Rest of world & 0.11 & 0.15 & 0.01 & 0.02 & 0.01 & 0.01 & 0.02 & 0.02 \\
\hline EPA natural defaults ${ }^{\mathrm{d}}$ & 0.12 & 0.23 & 0.10 & 0.10 & 0.02 & 0.02 & 0.47 & 1.40 \\
\hline
\end{tabular}

${ }^{\mathrm{a}}$ Concentrations are in $\mu \mathrm{g} \mathrm{m}^{-3}$. Values are annual means averaged at the ensemble of IMPROVE sites from the sensitivity simulations described in Section 2. Partitioning between west and east is at $95^{\circ} \mathrm{W}$. Background and natural concentrations are obtained from the sensitivity simulations without US and global anthropogenic emissions, respectively. Transboundary pollution influences from Canada and Mexico are determined by difference between two sensitivity simulations with anthropogenic emissions shut off in the USA versus in all of North America. Pollution influences from the rest of the world are determined by difference between two sensitivity simulations with anthropogenic sources shut off in all of North America versus globally. The ranges given for natural OMC aerosol concentrations correspond to the low and high limits discussed in Section 5.

${ }^{\mathrm{b}}$ Sulfate concentrations computed by the model are converted here to equivalent ammonium sulfate mass concentrations for consistency with the formulation of the Regional Haze Rule ( Eq . (2) ).

${ }^{\mathrm{c}}$ Organic carbon mass concentrations are derived by multiplying simulated OC concentrations by a factor of 1.4 (Malm et al., 1994).

d"Default average natural concentrations" recommended by US EPA (2003) for estimating natural visibility conditions as 2064 endpoint in the application of the EPA Regional Haze Rule. 

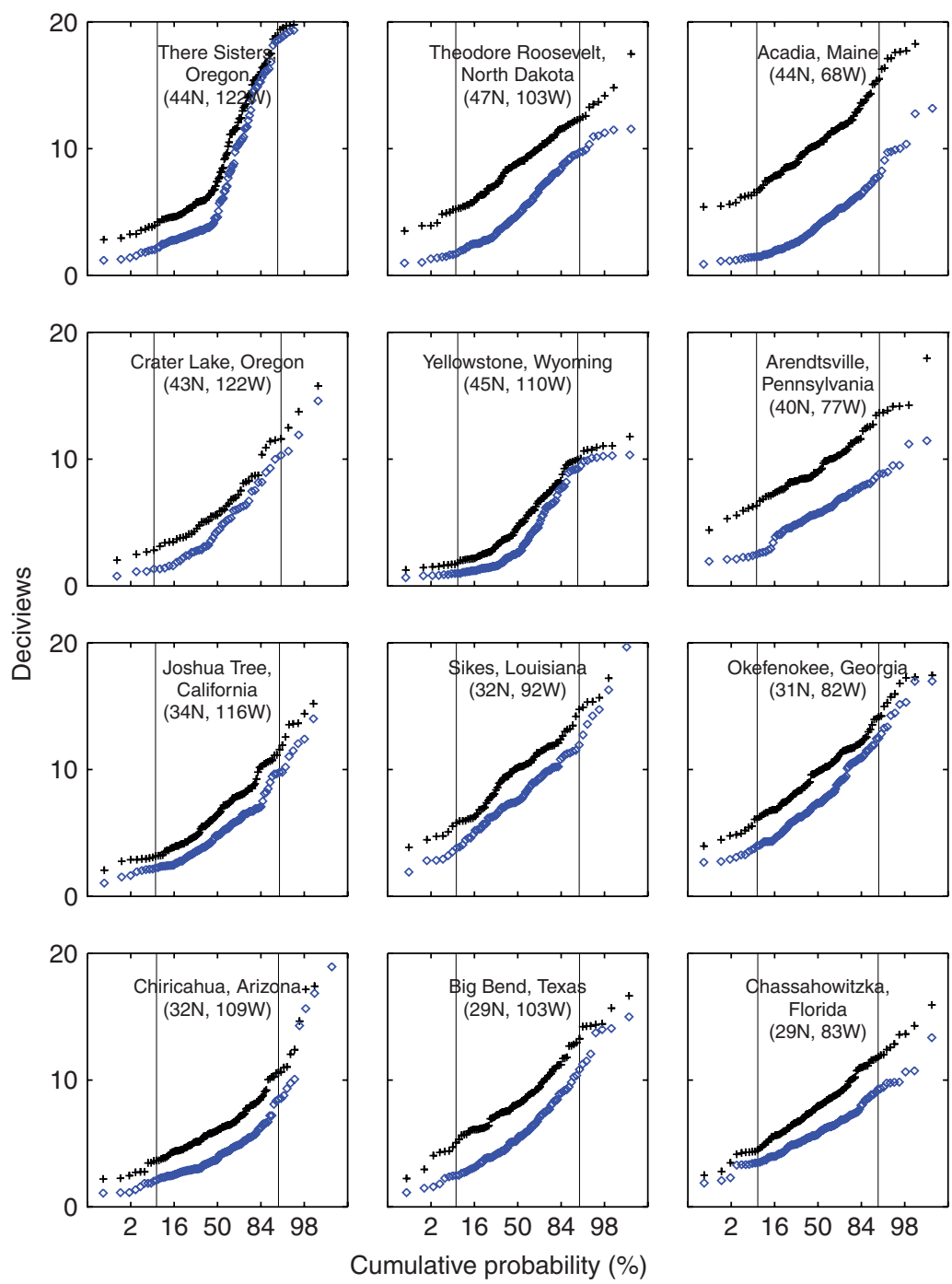

Fig. 9. Same as in Fig. 6 but for simulated natural (blue diamonds) and background (black pluses) visibility degradation (Haze Index) in deciviews. Background visibility degradation allows for both natural and transboundary pollution aerosols.

site endpoint visibility conditions in 2064 for application of the RHR. We compare in Fig. 10 our estimates with the EPA default values computed as described in Section 2. The higher EPA defaults in the east are driven by assumptions of higher mean natural $\mathrm{OC}$ and sulfate concentrations (Table 1), together with higher assumed standard deviations for these concentrations. As discussed in Section 6 and above, there is little basis for these assumptions. Our natural visibility endpoint estimates in Fig. 10 show considerable site-by-site variation. The highest values are in the northwest due to wildfires. Values in the east average $8.9 \mathrm{dv}$ and are much lower than the EPA default $(11.8 \mathrm{dv})$.
Transboundary pollution influences result in higher background visibility endpoints, more importantly in the northeast due to Canadian pollution influences. Our regional means for the background visibility endpoint are 11.2 and $13.2 \mathrm{dv}$ in the western and the eastern USA, respectively, higher than the EPA defaults.

\section{Implication for required emission reductions under the RHR}

We now use the results from section 7 to assess the implication of our results for phase 1 (2004-18) implementation of the RHR, following on the 


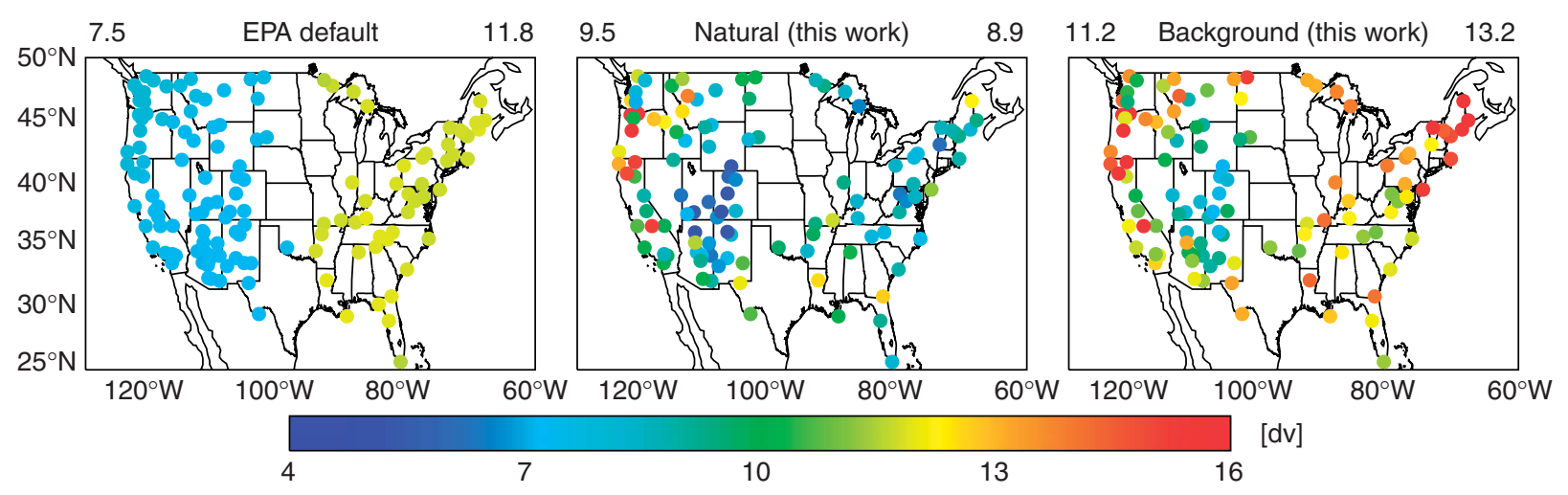

Fig. 10. Mean natural and background visibility degradation (Haze Index) for the $20 \%$ worst visibility days as 2064 endpoints for the application of the US EPA Regional Haze Rule. EPA default values for the means of the $20 \%$ worst days (left) are computed as the $92 \mathrm{nd}$ percentiles of the probability distributions for natural visibility degradation, using default values for the means and standard deviations of natural visibility degradation in the west and east as recommended by the RHR document (EPA, 2003). Simulated natural (middle) and background (right) values from our work are averages of the upper $20 \%$ of the probability distributions of daily visibility degradation from the model sensitivity simulations with anthropogenic emissions shut off globally and in the USA, respectively. Regional averages (west vs. east) over the ensemble of sites divided at $95^{\circ} \mathrm{W}$ are shown on top of each panel.

previous analysis by Park et al. (2004). We revise this analysis not only to reflect improvements in the model but also to make it specifically relevant to the RHR metric of mean visibility degradation for the $20 \%$ worst visibility days (Park et al. (2004) based their analysis on yearly mean visibility degradation). We compute baseline visibility degradation for the worst $20 \%$ days by applying Eqs. (1) and (2) in Section 2 to the daily IMPROVE observations in 2001. The resulting regional means of $20 \%$ worst baseline visibility degradation are 15 and $26 \mathrm{dv}$ in the western and eastern USA, respectively. We combine this with our estimates of natural and background visibility endpoints for 2064, as shown in Fig. 10, to infer the schedule of visibility improvements and hence emission reductions as required by the RHR.

Fig. 11 shows the trajectories of linear visibility improvement toward the 2064 natural visibility endpoints at the ensemble of IMPROVE sites in the western and the eastern USA. Following these trajectories, we find that visibility degradation during the 2004-18 phase1 implementation of the RHR should be reduced by $1.3 \mathrm{dv}$ (west) and $3.9 \mathrm{dv}$ (east) if our estimate of the 2064 natural visibility endpoint is used, and by $1.8 \mathrm{dv}$ (west) and $3.3 \mathrm{dv}$ (east) if the EPA default endpoint is used.

To estimate the required percentage reductions in US anthropogenic emissions needed to achieve such improvements, we assume a linear correspondence between aerosol extinction and emissions, and assume no changes in transboundary pollution in the future. The current aerosol extinction from US anthropogenic emissions can be calculated from the data in Table 1 by subtracting the background from the baseline aerosol concentrations, and applying Eq. (2). We obtain values of $11 \mathrm{Mm}^{-1}$ in the west and $105 \mathrm{Mm}^{-1}$ in the east. The resulting percentage decreases of US anthropogenic emissions required over 2004-18 are shown in Fig. 11. They are 38\% and $45 \%$ for the western and eastern USA, respectively, using our natural visibility endpoint, and $50 \%$ and $39 \%$, respectively, using the EPA natural visibility endpoint.

However, a natural visibility endpoint is unrealistic because of transboundary pollution. The RHR needs to be amended either by engaging other countries (in particular Canada and Mexico) in emission reductions, or by relaxing the endpoint to a background visibility condition allowing for transboundary pollution influence. Using background visibility as 2064 endpoint has major implications for phase 1 (2004-18) emission controls. The corresponding percentage decreases of US anthropogenic emission are $27 \%$ and $36 \%$ in the western and the eastern USA, respectively. These values are lower than those computed for the natural visibility endpoint especially in the western USA. In the east, our estimate of emission reduction toward the background endpoint happens to be consistent with that toward the EPA natural default 

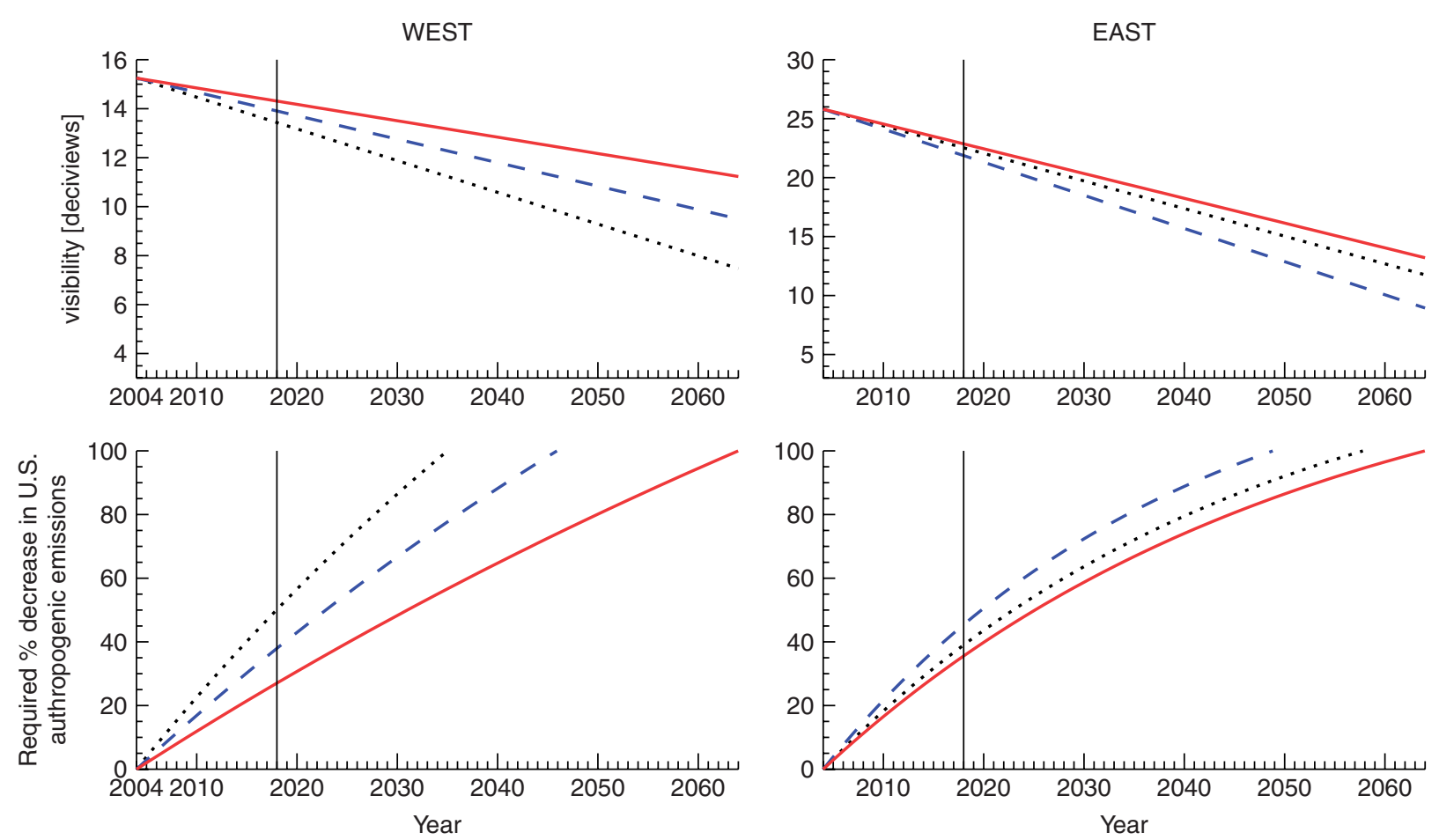

$$
\begin{aligned}
& \text { Specification of } 2064 \text { endpoint: } \\
& - \text { background (this work) } \\
& -\ldots-\text { natural (this work) } \\
& \ldots \ldots . \text { natural (EPA default value) }
\end{aligned}
$$

Fig. 11. Required visibility improvements and implied US anthropogenic emission reductions over the 2004-2064 period for the western and eastern USA under the Regional Haze Rule. The required percentage decrease in emissions corresponding to a given visibility improvement is computed by assuming a linear correspondence between aerosol extinction and emissions. Results are shown for different choices for the 2064 endpoint: (1) EPA natural default visibility (black dotted lines), (2) our estimate of natural visibility (blue dashed lines), and (3) our estimate of background visibility (red solid line). Background includes contributions from both natural and transboundary pollution sources. Year 2018 (vertical line) is the end date of phase 1 implementation of the RHR.

but that is only because the EPA natural default is too high.

Although the current formulation of the RHR assumes separation only between west and east for purpose of computing natural visibility statistics, Fig. 10 shows that natural and background visibility endpoints have in fact large spatial variability and need to be computed on a site-by-site basis. For example, if a natural endpoint is used, sites in the northwest and southeast should require weaker emission reductions than sites in the northeast and southwest at least over 2004-18 because of limitations to natural visibility from fires and biogenic emissions. If a background endpoint is used, all sites would require weaker emission reductions but particularly the northeast and southwest due to influences from Canada and Mexico, respectively.

\section{Conclusions}

We have used a global 3-D chemical transport model for aerosol-oxidant chemistry (GEOSChem), together with observations from the IMPROVE network of US surface sites, to examine visibility degradation statistics in the USA and their sensitivity to domestic and foreign anthropogenic emissions. This work was conducted to guide implementation of the US EPA Regional Haze Rule, which mandates linear improvement in visibility in wilderness areas during 2004-18 toward an endpoint of natural visibility in 2064. The linear improvement is measured by a Haze Index in units of deciviews ( $\log$ of aerosol extinction, computed from speciated aerosol concentrations) and applied to mean visibility for the statistically $20 \%$ worst 
days. Implementation of the Rule requires estimates of natural visibility statistics in different regions of the USA, and needs to acknowledge the role of transboundary transport of pollution in limiting the degree to which natural visibility can be approached solely from domestic emission reductions. We distinguish here between natural conditions defined by global suppression of anthropogenic emissions vs. background conditions defined by suppression of anthropogenic emissions in the USA only.

Our work built on the previous GEOS-Chem model study by Park et al. (2004), which estimated mean natural and background aerosol concentrations in the USA for purpose of visibility calculations. Park et al. (2004) used an older and coarser version of GEOS-Chem, and confined their attention to mean visibility averaged over the ensemble of western and eastern US sites. The present version has finer $\left(1^{\circ} \times 1^{\circ}\right)$ horizontal resolution over North America, and features a number of improvements including updated anthropogenic emissions (in particular for Canada and Mexico), better treatment of dry deposition (applied to the mixing depth rather than to the model surface layer), and a mechanistic approach to SOA formation. The higher model resolution is exploited here to examine spatial and temporal variability of visibility. This is important both for evaluating the model and for providing statistics with direct application to the Regional Haze Rule.

Comparisons of model results with observed seasonal distributions of sulfate, nitrate, ammonium, and carbonaceous aerosol concentrations at 135 IMPROVE sites across the USA for 2001 (79 CASTNET sites for ammonium) indicate no significant mean model bias. The model reproduces the observed spatial variability for sulfate and ammonium ( $R^{2}$ values of $\left.0.8-0.9\right)$ but has less success for nitrate and carbonaceous aerosols $\left(R^{2}\right.$ values of typically $0.3-0.5)$. The simulations of ammonium and nitrate show much improvement relative to Park et al. (2004) due to better treatment of dry deposition and heterogeneous chemistry. Errors with carbonaceous aerosols reflect in part the non-accounting of emissions from specific 2001 wildfires. The simulated spatial distribution of annual mean present-day visibility degradation (in deciviews) shows high correlation with observed values $\left(R^{2}=0.88\right)$ and a $10 \%$ mean positive bias. The largest model error is in southern California where nitrate aerosol is a major visibility reducing agent.
We examined the ability of the model to simulate the temporal variability of visibility degradation at individual US sites by using the daily observations over the course of 2001. The standard deviation of visibility degradation is highest in the northeast, and there are also some high values in the west associated with fires. The model reproduces the observed standard deviations at individual sites with little mean bias $(+10 \%)$ and high spatial correlation $\left(R^{2}=0.66\right)$, which gives confidence in using the model as a tool to diagnose variability in visibility. Visibility statistics at individual sites indicate a generally normal frequency distribution of visibility degradation, with the exception of western US sites affected by wildfire episodes. The model captures the low tails of the observed frequency distributions, lending support to its simulation of natural and background visibility conditions.

Natural visibility degradation in the model shows considerable variability, spatial and temporal, in particular because of wildfires, which also cause a large departure from normality in the visibility statistics. Compared to the EPA default estimates recommended for use in the Regional Haze Rule, our estimates of natural visibility degradation are higher in the west but lower in the east. We find that a major factor of uncertainty in estimating natural visibility is the sensitivity of biogenic SOA formation to the availability of anthropogenic aerosol. Background visibility degradation (including the effects of transboundary pollution) shows more variability than natural visibility degradation, especially in the eastern USA.

Transboundary transport of pollution makes the Regional Haze Rule 2064 endpoint of natural visibility conditions unattainable from domestic emission reductions alone. The definition of this desired endpoint also has a major impact on the schedule of emission reductions for Phase 1 of the Rule (2004-18). In an illustrative calculation using the visibility metrics of the Rule for the western USA, we find that using natural visibility as a 2064 endpoint would require a $50 \%$ reduction of anthropogenic US emissions over 2004-18 if the EPA default natural visibility estimates are used, and a 38\% reduction if our natural visibility estimates are used. Acknowledging the effect of uncontrollable transboundary pollution in the definition of the 2064 endpoint would result in a significantly slower schedule for reduction in US anthropogenic emissions over the 2004-18 period. 
Although the current formulation of the Regional Haze Rule only distinguishes between western and eastern USA for purpose of computing natural visibility statistics, we find that natural and background visibility have large spatial variability and need to be estimated on a site-by-site basis. If a natural visibility endpoint is used for application of the Rule, sites in the northwest and southeast should require weaker emission reductions than sites in the northeast and southwest at least for phase 1 (2004-18) because of limitations to natural visibility from fires and biogenic emissions. If a background endpoint is used, all sites would require weaker emission reductions but particularly the northeast and southwest due to influences from Canada and Mexico.

As the Regional Haze Rule moves into its implementation phase, there is a need to clarify its visibility improvement objectives for wilderness areas in the USA. Either one has to allow for uncontrollable transboundary pollution in preventing natural visibility conditions from being approached, or one has to engage other countries (particularly Canada and Mexico, but also East Asian) in reducing their own anthropogenic emissions. Further work is also needed to assess how future changes in foreign anthropogenic emissions, climate, and wildfire frequency will affect visibility improvements under the Rule.

\section{Acknowledgments}

This work was supported by the Electric Power Research Institute (EPRI). Development of the GEOS-Chem model is supported by the Atmospheric Chemistry Modeling and Analysis Program (ACMAP) of the National Aeronautics and Space Administration (NASA).

\section{References}

Ames, R.B., Malm, W.C., 2001a. Recommendations for natural condition deciview variability: an examination of IMPROVE data frequency distributions. In: Proceedings (CD-ROM) of A\&WMA/AGU Specialty Conference on Regional Haze and Global Radiation Balance-Aerosol Measurements and Models: Closure, Reconciliation and Evaluation, October 2-5, Bend, Oregon, 2001.

Ames, R.B., Malm, W.C., 2001b. Chemical species' contributions to the upper extremes of aerosol fine mass. Atmospheric Environment 35, 5193-5204.
Andreae, M.O., Merlet, P., 2001. Emission of trace gases and aerosols from biomass burning. Global Biogeochemical Cycles 15 (4), 955-966.

Aneja, V.P., Chauhan, J.P., Walker, J.T., 2000. Characterization of atmospheric ammonia emissions from swine waste storage and treatment lagoons. Journal of Geophysical Research 105 (D9), 11,535-11,545.

Battye, W., Aneja, V.P., Roelle, P.A., 2003. Evaluation and improvement of ammonia emissions inventories. Atmospheric Environment 37, 3873-3883.

Bertschi, I.T., Jaffe, D.A., Jaeglé, L., Price, H.U., Dennison, J.B., 2004. PHOBEA/ITCT 2002 airborne observations of transpacific transport of ozone, $\mathrm{CO}$, volatile organic compounds, and aerosols to the northeast Pacific: impacts of Asian anthropogenic and Siberian boreal fire emissions. Journal of Geophysical Research 109, D23S12.

Bond, T.C., Streets, D.G., Yarber, K.F., Nelson, S.M., Woo, J.-H., Klimont, Z., 2004. A technology-based global inventory of black and organic carbon emissions from combustion. Journal of Geophysical Research 109, D14203.

Bouwman, A.F., Lee, D.S., Asman, W.A.H., Dentener, F.J., VanderHoek, K.W., Olivier, J.G.J., 1997. A global highresolution emission inventory for ammonia. Global Biogeochemical Cycles 11 (4), 561-587.

Chin, M., Ginoux, P., Kinne, S., Torres, O., Holben, B., Duncan, B.N., Martin, R.V., Logan, J.A., Higurashi, A., Nakajima, T., 2002. Tropospheric aerosol optical thickness from the GOCART model and comparisons with satellite and sunphotometer measurements. Journal of Atmospheric Science 59, 461-483.

Chung, S.H., Seinfeld, J.H., 2002. Global distribution and climate forcing of carbonaceous aerosols. Journal of Geophysical Research 107 (D19), 4407.

Cooke, W.F., Liousse, C., Cachier, H., Feichter, J., 1999. Construction of a $1^{\circ} \times 1^{\circ}$ fossil fuel emission data set for carbonaceous aerosol and implementation and radiative impact in the ECHAM-4 model. Journal of Geophysical Research 104, 22,137-22,162.

Corbett, J.J., Fischbeck, P.S., Pandis, S.N., 1999. Global nitrogen and sulfur inventories for oceangoing ships. Journal of Geophysical Research 104, 3457-3470.

Duncan, B.N., Martin, R.V., Staudt, A.C., Yevich, R., Logan, J.A., 2003. Interannual and seasonal variability of biomass burning emissions constrained by satellite observations. Journal of Geophysical Research 108, 4040.

ERG, 2003. Mexico National Emissions Inventory, 1999, Prepared for Secretariat of the Environment and Natural Resources and the National Institute of Ecology of Mexico, United States Environmental Protection Agency, Western Governors' Association and North American Commission for Environmental Cooperation, ERG, Sacramento, CA.

Evans, M.J., Jacob, D.J., 2005. Impact of new laboratory studies of N2O5 hydrolysis on global model budgets of tropospheric nitrogen oxides, ozone, and $\mathrm{OH}$. Geophysical Research Letters 32, L09813.

Gilliland, A.B., Dennis, R.L., Roselle, S.J., Pierce, T.E., 2003. Seasonal $\mathrm{NH}_{3}$ emission estimates for the eastern United States based on ammonium wet concentrations and an inverse modeling method. Journal of Geophysical Research 108 (D15), 4477. 
Guenther, A., et al., 1995. A global model of natural volatile organic compound emission. Journal of Geophysical Research 100, 8873-8892.

Guenther, A., Karl, T., Harley, P., Wiedinmyer, C., Palmer, P.I., Geron, C., 2006. Estimates of global terrestrial isoprene emissions using MEGAN (Model of Emissions of Gases and Aerosols from Nature). Atmospheric Chemistry and Physics Discussions 6, 107-173.

Hansen, D.A., Edgerton, E.S., Hartsell, B.E., Jansen, J.J., Kandasamy, N., Hidy, G.M., Blanchard, C.L., 2003. The SouthEastern Aerosol Research and CHaracterization study: Part 1. Overview. Journal of the Air and Waste Management Association 53, 1460-1471.

Heald, C.L., Jacob, D.J., Park, R.J., Russell, L.M., Huebert, B.J., Seinfeld, J.H., Liao, H., Weber, R.J., 2005. A large organic aerosol source in the free troposphere missing from current models. Geophysical Research Letters 32, L18809.

Held, T., Ying, Q., Kaduwela, A., Kleeman, M., 2004. Modeling particulate matter in the San Joaquin Valley with a sourceoriented externally mixed three-dimensional photochemical grid model. Atmospheric Environment 38, 3689-3711.

Hirsch, R.M., Gilroy, E.J., 1984. Methods of fitting a straight line to data: examples in water resourses. Water Research Bulletin 20, 705-711.

Hughes, L.S., Allen, J.O., Bhave, P., Kleeman, M.J., Cass, G.R., 2000. Evolution of atmospheric particles along trajectories crossing the Los Angeles basin. Environmental Science and Technology 34 (15), 3058-3068.

Hughes, L.S., Allen, J.O., Salmon, L.G., Mayo, P.R., Johnson, R.J., 2002. Evolution of nitrogen species air pollutants along trajectories crossing the Los Angeles Area. Environmental Science and Technology 36, 3928-3935.

Jacob, D.J., 2000. Heterogeneous chemistry and tropospheric ozone. Atmospheric Environment 34, 2131-2159.

Jaffe, D., Anderson, T., Covert, D., Kotchenruther, R., Trost, B., Danielson, J., Simpson, W., Berntsen, T., Karlsdottir, S., Blake, D., Harris, J., Carmichael, G., Uno, I., 1999. Transport of Asian air pollution to North America. Geophysical Research Letters 26 (6), 711-714.

Jaffe, D., McKendry, I., Anderson, T., Price, H., 2003. Six 'new' episodes of trans-Pacific transport of air pollutants. Atmospheric Environment 37 (3), 391-404.

Kavouras, I.G., Stephanou, E.G., 2002. Direct evidence of atmophseric sercondary organic formation in forest atmosphere through heteromolecular nucleation. Environmental Science and Technology 36, 5083-5091.

Kleeman, M.J., Hughes, L.S., Allen, J.O., Cass, G.R., 1999. Source contributions to the size and composition distribution of atmospheric particles: Southern California in September 1996. Environmental Science and Technology 33, 4331-4341.

Kuhns, H., Knipping, E.M., Vukovich, J.M., 2005. Development of a United States-Mexico Emissions Inventory for the Big Bend Regional Aerosol and Visibility Observational (BRAVO) Study. Journal of the Air and Waste Management Association 55, 677-692.

Lavery, T.F., Rogers, C.M., Kemp Howell, H., Burnett, M.C., Wanta, C.A., Stewart, M.O., 2002. Clean Air Status and Trends Network (CASTNet) 2001 Annual Report.

Liu, H., Jacob, D.J., Bey, I., Yantosca, R.M., 2001. Constraints from ${ }^{210} \mathrm{~Pb}$ and ${ }^{7} \mathrm{Be}$ on wet deposition and transport in a global three-dimensional chemical tracer model driven by assimilated meteorological fields. Journal of Geophysical Research 106, 12,109-12,128.

Malm, W.C., Day, D.E., 2001. Estimates of aerosol species scattering characteristics as a function of relative humidity. Atmospheric Environment 35, 2845-2860.

Malm, W.C., Sisler, J.F., Huffman, D., Eldred, R.A., Cahill, T.A., 1994. Spatial and seasonal trends in particle concentration and optical extinction in the United States. Journal of Geophysical Research 99, 1347-1370.

Malm, W.C., Pitchford, M.L., Scruggs, M., Sisler, J.F., Ames, R., Copeland, S., Gebhart, K.A., Day, D.E., 2000. Spatial and Seasonal Patterns and Temporal Variability of Haze and its Consituents in the United States: Report III, Cooperative Institute for Research in the Atmosphere, Colorado State University, Fort Collins, Colorado.

Malm, W.C., Day, D.E., Kreidenweis, S.M., Collett, J.L., Lee, T., 2003. Humidity-dependent optical properties of fine particles during the Big Bend Regional Aerosol and Visibility Observational Study. Journal of Geophysical Research 108 (D9), 4279.

Marti, J.J., Weber, R.J., McMurry, P.H., Eisele, F., Tanner, D., Jefferson, A., 1997. New particle formation at a remote continental site: Assessing the contributions of SO2 and organic precursors. Journal of Geophysical Research 102, 6331-6339.

Martin, R.V., Jacob, D.J., Yantosca, R.M., Chin, M., Ginoux, P., 2003. Global and regional decreases in tropospheric oxidants from photochemical effects of aerosols. Journal of Geophysical Research 108 (D3), 4097.

Neuman, J.A., et al., 2003. Variability in ammonium nitrate formation and nitric acid depletion with altitude and location over California. Journal of Geophysical Research 108 (D17), 4557.

O’Dowd, C.D., Aalto, P., Hameri, K., Kulmala, M., Hoffmann, T., 2002. Aerosol formation-atmospheric particles from organic vapours. Nature 416, 497-498.

Park, R.J., Jacob, D.J., Chin, M., Martin, R.V., 2003. Sources of carbonaceous aerosols over the United States and implications for natural visibility. Journal of Geophysical Research 108 (D12), 4355.

Park, R.J., Jacob, D.J., Field, B.D., Yantosca, R.M., Chin, M., 2004. Natural and transboundary pollution influences on sulfate-nitrate-ammonium aerosols in the United States: Implications for policy. Journal of Geophysical Research 109, D15204.

Park, R.J., et al., 2005. Export efficiency of black carbon aerosol in continental outflow: Global implications. Journal of Geophysical Research 110, D11205.

Pitchford, M.L., Malm, W.C., 1994. Development and applications of a standard visual index. Atmospheric Environment 28 (5), 1049-1054.

Pitchford, M.L., Tombach, I., Barna, M., Gebhart, K.A., Green, M.C., Knipping, E.M., Kumar, N., Malm, W.C., Pun, B., Schichtel, B.A., Seigneur, C., 2004. Big Bend Regional Aerosol and Visibility Observational study (BRAVO); Final Report. US Environmental Protection Agency Region VI, Dallas, TX.

Ryan, P.A., 2004. Review of the US Environmental Protection Agency Default Implementation Guideline for the Regional 
Haze Rule, report 1011119. Electrical Power Research Institute, Palo Alto, CA.

Singh, M., Jaques, P.A., Sioutas, C., 2002. Size distribution and diurnal characteristics of particle-bound metals in source and receptor sites of the Los Angeles Basin. Atmospheric Environment 36, 1675-1689.

Tombach, I., Brewer, P., 2005. Natural Background Visibility and Regional Haze Goals in the Southeastern United States. Journal of the Air and Waste Management Association 55, $1600-1620$.

US EPA, 2003. Guidance for Estimating Natural Visibility Conditions Under the Regional Haze Rule, US EPA OAQPS report, EPA 454/B-03-005, Research Triangle Park, NC.

Vestreng, V., et al., 2004. Inventory Review 2004, Emission Data reported to CLRTAP and under the NEC Directive, EMEP/ EEA Joint Review Report, EMEP/MSC-W Note 1/2004. ISSN:0804-2446.
Wang, Y.X., McElroy, M.B., Jacob, D.J., Yantosca, R.M., 2004. A nested grid formulation for chemical transport over Asia: applications to CO. Journal of Geophysical Research 109, D22307.

Wang, Y., Jacob, D.J., Logan, J.A., 1998. Global simulation of tropospheric $\mathrm{O}_{3}-\mathrm{NO}_{x}$-hydrocarbon chemistry, 1. Model formulation. Journal of Geophysical Research 103 (D9), $10,713-10,726$.

Wesely, M.L., 1989. Parameterization of surface resistance to gaseous dry deposition in regional-scale numerical models. Atmospheric Environment 23, 1293-1304.

Whitby, K.T., 1978. The physical characteristics of sulfur aerosols. Atmospheric Environment 12, 135-159.

Ying, Q.I., Mysliwiec, M., Kleeman, M.J., 2004. Source apportionment of visibility impairment using a three-dimensional source-oriented air quality model. Environmental Science and Technology 38, 1089-1101. 